\title{
Dynamics of Child Health Services in Nigeria: A Review
}

\author{
B. O. Ogbonna ${ }^{1 *}$, N. Ajagu' ', L. N. Ezenekwe' ${ }^{1}$ C. P. Isidienu' ', C. E. Ejim² and O. L. Nwankwo' \\ 'Department of Clinical Pharmacy and Pharmacy Management, Faculty of Pharmaceutical Sciences, Nnamdi \\ Azikiwe University, Awka, Nigeria; bo.ogbonna@unizik.edu.ng \\ 2Pharmacy Department, Enugu State University Teaching Hospital, Enugu, Nigeria
}

\begin{abstract}
Childcare has been identified as an integral aspect of integrated maternal and child health services and is aimed at child health promotion for childhood psychosocial and physical development. This study assessed the dynamics of child health services in Nigeria. This was in relation to Nigeria's poor child health indices with the view to encouraging standard practices neglected over the years. It targets preventive health services to stem diseases and disability among children while promoting early diagnosis of diseases and prompt treatment. These services encompass the provision of childhood immunization, probing for and identification of handicapped children for early rehabilitation, child health education, and nutrition, promotion of environmental sanitation, and monitoring of developmental milestone through proper feeding. Other child health services include sickle cell prevention services, education of caregivers on the importance and use of oral rehydration therapy, and use of antimalarial treatment, and rehabilitation of already affected children. This is invaluable, especially in regions with developing countries where more than $50 \%$ of children die before their fifth birthday.
\end{abstract}

Keywords: Childcare, Childhood, Healthcare, Immunization, Mortality, Nigeria, Nutrition, Policy

\section{Introduction}

Childhood immunization is the process whereby a child is made immune or resistant to an infectious disease typically by the administration of vaccines, vaccines stimulate the body's own immune system to protect the child against subsequent infection of diseases. Four decades ago, in 1974, the World Health Organization (WHO) launched the Expanded Program on Immunization (EPI); this was introduced in Nigeria in 1979. From 1979-1997, the program was known and was also called Expanded Program on Immunization (EPI) ${ }^{1}$. The EPI blueprint laid out the technical and managerial functions necessary to vaccinate children routinely with a limited number of vaccines, providing protection against diphtheria, tetanus, whooping cough, measles, polio, and tuberculosis, and to prevent maternal and neonatal tetanus by vaccinating women of childbearing age with tetanus toxoid. The purpose of EPI was simple and straightforward to deliver multiple vaccines to all children through a simple schedule of child health visits ${ }^{1}$. At the time, basic health systems in most lower and lower-middle income countries (LLMICs) were weak to nonexistent. Vaccine coverage levels among children younger than one year of age were less than $5 \%^{2}$.By 1990, most LLMICs had institutionalized immunization programs were based the EPI blueprint. The vision of EPI in Nigeria is to improve the health of Nigerian children by eradicating all the identified six killer diseases, which are polio, measles, diphtheria, whooping cough, tuberculosis, and yellow fever. Between 1985 and 1990, as contained in the National Health Plan for that period, the objectives of EPI were to strengthen immunization; accelerating disease control and introducing new vaccines and relevant technologies, and tools ${ }^{3}$.This study assessed the dynamics of child health services in Nigeria with the view to encouraging standard practices and policies neglected over the years, which have negatively influenced our health outcomes.

${ }^{*}$ Author for correspondence 


\section{Immunization and Child Health}

In line with the above, Nigeria in 1995, being a signatory to World Health Assembly, adopted the World Health Assembly Resolution (WHAR) and to give a national outlook and show Federal Government in 1997 in commitment, the Federal Govt. established an agency called NPI under Decree 12 in August 1997. This is to control the occurrence of all vaccine preventable diseases through immunization and provision of vaccine and other consumable effectively. The focus is on prevention, control and eradication of the following vaccine preventable disease in Nigeria i.e. tuberculosis, measles, diphtheria, pertussis, neonatal tetanus, cerebro-spinal meningitis, yellow fever and polio ${ }^{4}$. These are targeted through immunization service delivery and this is done by administration of a vaccine to susceptible target. NPI aim the following group of people: children of age $11 \mathrm{months}$, all pregnant women, and women of reproducing age group. At birth, oral polio vaccine(OPV), hepatitis B vaccine (HBV), Bacillus Calmette Guerin (BCG)is given. After6weeks:OPV,diphtheria, pertussis and tetanus (DPT), HBV; After 10weeks: OPV, DPT; after14weeks:OPV, DPT, HBV; in9months,measles, yellow fever, vitamin A, and in 15 months:vitamin A. In pregnant women, or women in reproductive age group:tetanus toxoid TT1 is given as the firstdosefor those with a form of immunization. TT2 is given at 4 weeks later,offers $80 \%$ protection for 3years, TT3 is given at 6 months later, $95 \%$ protection for 5 years, TT4,1year later or in subsequent pregnancy to offer 99\% protection for 10 years while TT5 is given one year later or in subsequent pregnancy, 99\% protection for life ${ }^{16}$.

\section{Millennium Development Goals and Child Health}

United Nations General Assembly Special Session (UNGASS) has goals that by 2005 , all countries must achieve: (i)Polio Eradication, (ii)Measles Mortality Reduction, (iii)Maternal and Neonatal Tetanus Elimination $(\mathrm{MNTE})^{5}$. Nigeria also adopted the Millennium Development Goals (MDGs) that: Two-third reductions in child mortality, as compared to 1990, should be achieved by the year 2005. In addition to the above, the country similarly ratified the United Nations General Assembly General Assembly ${ }^{6}$. Special Session (UNGASS) goals, that by 2010, Nigeria should aim atensuring full immunization of children under one year of age at $90 \%$ coverage nationally with at least $80 \%$ coverage in every district or equivalent administrative unit, and Vitamin A deficiency elimination.

From the foregoing, Nigeria drew her core activities of her NPI policies in 1998. These activities include monitoring of the performance, quality, and safety of the immunization system through indicators, assessment of the current burden of vaccine preventable diseases as well as the "future" burden of vaccine preventable diseases in terms of sickness, death, and disability, and the economic burden. This is in addition to assessment of the impact of vaccination strategies, through on-going epidemiological surveillance and reliable laboratory confirmations and impact assessments, monitoring of the National Immunization policies, particularly the vaccines being used within the country, and the target population for these vaccines (immunization schedules). Monitoring of the overall proportion of children, and women who are vaccinated (immunization coverage) and ensuring that all districts of the country are well covered by vaccination is ensured ${ }^{7}$.

The Federal Ministry of Health in 2000, following the African Regional Summit on NPI, held in Harare in November 1999, specifically stated its policies on the country's initial visions for NPI as follows:

(i) Immunization System Strengthening: By the year 2004, Nigeria should have achieved NPI district focused plan and attained $80 \%$ DPT3 coverage in all the states of the federation. The specific policy also stated that the government should ensure increased funding for $\mathrm{NPI}^{8}$.

(ii) Accelerated Disease Control: By the year 2004, there should be no cases of acute flaccid paralysis associated with wild poliovirus in Nigeria. As for measles, by the year 2004 , the country should have reduced measles morbidity by $90 \%$ and measles mortality by $95 \%$; while the coverage for yellow fever is expected to increase to at least $80 \%$.

(iii) Innovations: That by the year 2004, Nigeria should include Vitamin A and Hepatitis B (HB) in its national immunization programs, and the vaccination coverage should not be less than $80 \%$ coverage as in other antigens. Under the new technologies drive, the country should adopt the multi-dose vial policy (MDVP) and vaccine vial monitor (VVM) and introduce new methods for monitoring its use ${ }^{10}$. 
This policy framework indicated clear vision towards ensuring child survival from the killer diseases in Nigeria. The government sets a target of reducing child mortality due to immunizable diseases to $5 \%$ by the year $2004^{11}$. This is achievable, as the government policies on NPI indicated, by covering not less than $80 \%$ of all the antigens in all the states of the federation in Nigeria. In fact, the government meant to cover $95 \%$ coverage on measles antigen in the year $2004^{12}$. As of July, the year 2005, Nigeria is still one of the highest polio infected countries of the World. As noted above, Nigeria ranked third among the remaining six countries of the world still battling with polio infections. Similarly, the incidence of TB is still common, although this is attributed to AIDS infection, yet since some child morbidity and mortality are still due to $\mathrm{TB}$ infection ${ }^{13}$.It implies that $\mathrm{TB}$ vaccination has not yet achieved the country's desired vision ${ }^{14}$.

\section{Current Immunization Status}

In 2014, WHO recommended that all immunization programs should add vaccines against hepatitis B, Haemophilusinfluenzae type b, Streptococcus pneumoniae, rotavirus, rubella, and human papillomavirus (in girls). However, the full benefits of these vaccines have yet to be realized $^{15}$. WHO estimates $29 \%$ of deaths among children 1-59 months of agearevaccine-preventable ${ }^{16}$. This gap is due largely to systems weaknesses in immunization programs that can be improved. With the addition of new vaccines, the complexity and costs of routine immunization increase ${ }^{17}$.More vaccinations to protect against more diseases require additional and better communication between health workers and caregivers as well as greater cold chain capacity ${ }^{18}$. New vaccines and doses that expand immunization beyond infancy extend the benefits of vaccines across the life spectrum into adolescence and adulthood ${ }^{19}$.Moreover, health systems, in general, are becoming more complex as new programs and services were added. Fulfilling the vision of NPI requires sustained investments in routine immunization. Since its inception, expanded immunization has been a continuous and progressive story building on the fundamental managerial and technical health systems, building blocks of leadership and governance; financing; service delivery; health workforce; products, vaccines, and technologies; and information systems ${ }^{8,20}$.
Additionally, the economic benefits of immunization are significant ${ }^{21}$. Healthier individuals are, in the long term, more productive contributors to a country's wealth, particularly as countries rapidly transition from high to lower mortality levels despite substantial success, there remain numerous challenges to the ultimate effectiveness of routine immunization. These fall into the following programmatic areas: (a) policy, standards, and guidelines; (b) governance, organization, and management; (c) human resources; $(d)$ vaccine, cold chain, and logistics management; $(e)$ service delivery; $(f)$ communication and community partnerships; $(g)$ data generation and use; and $(h)$ sustainable financing ${ }^{9,21}$.

The major challenges confronting the use of childhood vaccines in Nigeria include lack of disease burden data, weak health systems and its attendant poor logistics such as cold chain, poor transportation and storage systems, inadequate and poorly motivated health care worker and lack of political will. Others are barriers to using of "new" vaccines, poor health financing, weak community participation, and lack of sustainable partnerships.

\section{Child Health Services in Nigeria; Issues in Perspective and Prospects}

Child health services are provisions made to improve optimal growth and development in infancy and childhood through disease prevention, good nutrition, and health supervision ${ }^{22}$. Child health care is services, which focus on the well-being of children from conception. It is concerned with all aspects of children's growth and development with the unique opportunities so that each child will achieve his or her full potential as a healthy adult ${ }^{23}$. Childcare services are total care and services rendered to under five children in order to maintain their healthy living ${ }^{24}$.Therefore, child health care services are efficient strategies provided by health workers in order to promote health and prevent diseases, disabilities, and death in children through simple costeffective measures. A healthy child's development actually begins with the parents, and once a baby is delivered, other matters such as breastfeeding, newborn screening tests, sleeping safety, health care appointments for checkups and immunizations are considered ${ }^{23}$. As 
services are provisions made for the public to use as much as they need in order to benefit from them, the purpose of child health care in health facilities is to promote the health of children, provide support in maintaining and improving children's health through counseling, medical examination, treatment, and immunization.

Child health is a critical issue of concern to everyone and at the level of the family, the community, the nation, and the international community. This is because successful societies safeguard their future by continually striving to improve the well-being of their children. They understand that a healthy, well developed educated and respected progeny ensures that achievements serve as the foundation for continuing progress ${ }^{22}$. In order to improve health outcomes of children there should be a more effective organization of preventive services and more coordination between practices. Intervention to achieve an effect on children and to overcome specific barriers in the process of care delivery needs to be adapted so that preventive services could be effectively delivered. Therefore, changes in the organization of the delivery system that concerns children will lead to improvement in their preventive health outcomes ${ }^{25}$.

International communities and individual countries are repeatedly committed to improving child health. WHO in 2004, stated that this commitment needs to be translated into stronger action if the silent tragedy of preventable death, illness, disability and impaired psychosocial development among children are to be avoided, and if the children's quality of life is to be improved. Improving child health development relies, largely, on understanding the causes of child morbidity and mortality with programs and policies aimed at improving the health of children. Twelve million children under five years of age in developing countries die annually before their fifth birthday and seventy percent of these deaths are due to five common preventable and easily treated childhood diseases. These diseases are acute respiratory infections, diarrhea, measles, malaria, and malnutrition or the combination of all five, which account for three-quarters of all childhood morbidity ${ }^{26}$. The field of pediatrics has been concerned with promoting children's health and development as with treating children's diseases, and the trend in children's health status showed that their physical health is better than it has ever been ${ }^{27}$. This is as a result of scientific progress, which has led to substantial reduction in many of the acute morbidities of the early 20th century and increasing survival from acute illness and premature births.

\section{Interventions for other Child Health Services Adopted in Nigeria}

- WHO, founded the Expanded Program on Immunization (EPI) in 1977 letter transformed to NPI in $1997^{28}$.

- The control of Diarrheal Diseases Program (CDD) was established in $1980^{29}$.

- Acute Respiratory Infection Program (ARI) was added to these vertical strategies IN $1985^{30}$.

With WHO technical support and UNICEF (United Nations Children's Fund) sponsorship, these three programs have been put in place and health workers are trained through workshops to recognize key signs of illnesses and to implement correct treatment and followup actions $s^{31}$.

- Child Survival Strategy in 1983, the International Pediatric Association Conference, James Grant the Executive Directors of UNICEF launched the Child Survival Revolution with emphasis on Growth Monitoring, Oral Rehydration Therapy, Breastfeeding, Immunization and Female Education and Family Spacing. The Nigerian Government actively participated in implementation of this Oral Rehydration Therapy; By 1993, the oral rehydration therapy, one of the components of the Child Survival Strategy not only became a household word but death from severe dehydration due to diarrhea disease declined. An example of this success story was recorded in Yola, General Hospital in the Gongola State, now called Adamawa State ${ }^{32}$. An ORT Demonstration Unit was established in May 1985. Between May and November 1984, the hospital recorded, 4,045 cases of childhood diarrhea admitted to the hospital for treatment. Of this number, 1,755 received intravenous fluid therapy and 79 died $^{33}$.

- Nigeria's Military Vice-President, attended the World Summit for Children of September 1990, held in New York. The summit, attended by 71 heads of states and government of nations set these targets for improvement of the child's health: polio eradication, 
elimination of neonatal tetanus (by 1995), reduction in measles cases by $90 \%$ and a $95 \%$ reduction in measles deaths to pre-immunization, halving child death caused by diarrhea, and $25 \%$ reduction in incidence of diarrheal disease. Others include onethird reduction of deaths caused by acute respiratory infections, elimination of guinea worm and vitamin A deficiency, reduction of low birth weight and promotion of growth monitoring ${ }^{34}$.Nigeria's attempt in actualizing these goals yielded below expectations except for Vitamin A fortifications and iodine salt ${ }^{35}$.

- In addition, WHO and UNICEF formulated a more recent strategy known as integrated management of childhood illnesses (IMCI) in 1996 as an additional and a principal strategy to improve child health, which concentrates on their overall health status by integrating all intervention for prevention, treatment, and health promotion ${ }^{36}$.

\section{Factors Affecting the Provision of Child Health Care Services}

The three major objectives of child health services include promoting the health of children and ensuring that they achieve optimal growth and development both physically and mentally. Others are protecting children from major hazards through specific measures (immunization, chemoprophylaxis, dietary supplements) and through improvement in the level of careprovided by the mothers and the family; and to treat diseases and disorders with particular emphasis on early diagnosis in order to provide effective remedy at an early stage before dangerous complications occur ${ }^{37}$.

Observation of a number of factors, which hampers the achievement of these objectives of child health care services, has been made by some authors who observed that staffs always want to do their best for children, but were hampered by a lack of staff system supports, which cause a delay for children in obtaining services ${ }^{38}$. WHO in2004, observed that the management and organization of the health system, public or private may be disorganized, leading to a lack of coordination among vertical program and projects, duplication of effort with the subsequent suboptimal utilization of available resources and inconsistency in technical guidelines among program. Challenges to delivering emergency care in poor resource settings are poor recruitment and retention of staff with a lack of training, inadequate equipment, and unsuitable work environment ${ }^{39}$. Many caregivers of children work twelve months in a year for long hours, therefore, getting the appropriate training and finding time to coordinate services for families or children is difficult. The barriers to providing the preventive services that are recommended to include time constraints; low level of reimbursement for preventive care and for developmental services; lack of training in child development and lack of trained nonphysician staff members ${ }^{40}$.

Also, identified are limited access to community services to support families and children, few external incentives are the reasons why the needs of children, and families for preventive and curative care were not met. Other reasons include poor knowledge by workers of other programs, crude and rude service providers, and no systematic means of identifying, tracking and ensuring that infants and families receive what they needed overtime effects the provision of services ${ }^{41}$.Standard and quality in child health care may be difficult when pay is low, the program cost is high and parents who need early intervention or childcare have limited resources.

\section{Conclusion}

The poor child health indices in Nigeria grappling with the prevailing poor socioeconomic indices, poor caregiver education, adverse cultural practices, and overall health indices have depleted child health services and increased childhood mortality. Standard childhood survival strategies were poorly funded over the years, coupled with poor policy implementation. These have affected the child health outcomes negatively. An integrated, proactive approach geared towards prompt immunization coverage and surveillance, caregiver education on breastfeeding, family planning, child nutrition and management of selflimiting conditions should be encouraged and properly funded. The Government should encourage the services of nongovernmental organizations and funding agencies by providing an enabling environment to facilitate grass root child health services. Policy monitoring, evaluation, and review of existing structures and templates should be encouraged by the government from the national to grass root level with sound feedback mechanisms put in place for tracking, modifications and follow-up. 


\section{Abbreviations}

OPV: Oral Polio Vaccine; TT: Tetanus Toxoid; CDD: Control of Diarrheal Disease; UNGASS: United Nations General Assembly; BCG: Bacillus Calmette Guerin; DPT: Diphtheria, Pertussis and Tetanus; IMCI: International Management of Childhood Illnesses; WHAR: World Health Assembly Resolution; LMICs: Lower Middle Income Countries; UNICEF: United Nations Children's Fund.

\section{Competing Interests}

The authors have no competing interest to declare.

\section{Funding}

There was no external funding provided for this article.

\section{References}

1. Chan $\mathrm{M}$. The contribution of immunization: saving millions of lives, and more. Public Health Rep. 2014; 129(3):7-8.

2. Chan M. Beyond expectations: 40 years of EPI. Lancet. 2014; 383(9930):1697-98.

3. World Health Organization (WHO). United Nations Children's Fund (UNICEF). Global immunization data. Geneva: WHO. 2016[cited 16 March 2016].Available from: http://www.who.int/immunization/monitoring_surveillance/global_immunization_data.pdf?ua51.

4. Duclos P. National Immunization Technical Advisory Groups (NITAGs): guidance for their establishment and strengthening. Vaccine. 2010; 28(1):18-25.

5. World Health Organization (WHO). The Global Vaccine Action Plan 2011-2020. Geneva: WHO; 2013[cited 26 March 2016].Available from: http://www.who. int/immunization/global_vaccine_action_plan/GVAP_ doc_2011_2020/en/index.html.

6. Steinglass R. Routine immunization: an essential but wobbly platform.Glob Health SciPract. 2013; 1(3):295-301.

7. Gilson L. Trust and the development of health care as a social institution. SocSci Med.2003; 56(7):1453-68.

8. Cairns KL, Perry RT, Ryman TK, Nandy RK, Grais RF. Should outbreak response immunization be recommended for measles outbreaks in middle- and low-income countries? An update. J Infect Dis. 2011; 2041:35-46.

9. Barbiero VK. It's not Ebola ... it's the systems. Global Health: Science and Practice. 2014; 2(4):374-5.

10. Decade of Vaccines (DoV) Collaboration Secretariat.
Decade of Vaccines Collaboration [Internet]. Barcelona (Spain): DoV Collaboration; 2014[cited 26 March 2016]. Available from:http://www.dovcollaboration.org.

11. Bloom DE, Canning D, Weston M. The value of vaccination. World Econ. 2005; 6(3):15-39.

12. Levin A, Kaddar M. Role of the private sector in the provision of immunization services in low- and middle-income countries. Health Policy Plan. 2011; 26(1):4-12.

13. Duclos P, Dumolard L, Abeysinghe N, Adjagba A, Janusz $\mathrm{CB}$, Mihigo R, et al. Progress in the establishment and strengthening of national immunization technical advisory groups: analysisfrom the $2013 \mathrm{WHO} / \mathrm{UNICEF}$ joint reporting form, data for 2012. Vaccine. 2013; 31(46):5314-20.

14. Steinglass R, Cherian T, Vandelaer J, Klemm RD, Sequeira J. Development, and use of the Lives Saved Tool (LiST): a model to estimate the impact of scaling up proven interventions on maternal, neonatal and child mortality. Int J Epidemiol. 2011;40(2):519-20.

15. Ozawa S, Stack ML, Bishai DM, Mirelman A, Friberg IK, Niessen L, et al. During the 'decade of vaccines', the lives of 6.4 million children valued at $\$ 231$ billion could be saved. Health Aff (Millwood). 2011; 30(6):1010-20.

16. Fields R. A stakeholder consultation on investment strategies for routine immunization in Africa. Arlington (VA): JSI Research and Training Institute; 2012[cited 02 April 2016]. Available from: http://arise.jsi.com/files/2012/11/ARISE_ StakeholderConsultation_final508.pdf 2011; 40(2):519-20.

17. UNICEF. Supplies and logistics: vaccine price data [Internet].New York: United Nations Children's Fund (UNICEF);2014 Aug 21[cited2016 March 18].Available from: http://www.unicef.org/supply/index_57476.html.

18. Zaffran M, Vandelaer J, Kristensen D, Melgaard B, Yadav P, Antwi-Agyei KO, et al. The imperative for stronger vaccine supply and logistics systems. Vaccine. 2013; 31(S2):73-80.

19. Rees CJ, Hossain F. Perspectives on decentralization and local governance in developing and transitional countries. Int J Public Adm. 2010; 33(12,13):581-7.

20. Hipgrave DB, Alderman KB, Anderson I, Soto EJ. Health sector priority setting at meso-level in lower and middle income countries: lessons learned, available options and suggested steps. SocSci Med. 2014; 102:190-200.

21. Maluka SO, Hurtig AK, Sebastián MS, Shayo E, Byskov J, Kamuzora P. Decentralization and health care prioritization process in Tanzania: from national rhetoric to local reality. Int J Health Plann Manage. 2011; 26(2):102-20.

22. McGlynn ES, Halfon N. Overview of issues in improving quality of health care for children. Health Services Research.1988: 33:977-1000.

23. Hetch BK, ShielWC. Children's health. Healthy kids Home Page:Children's Health Centre [Internet]. 2006. Available from:Medicine Net.com.

24. Onuzulike NM. Health care delivery systems.2nd ed.Owerri: Megasoft publishers; 2005.

25. Margolis PA, Steven R, BordleyWC, Stuart J, Harlon C, 
Keyes EL, Stein L, Wisseh S. From concept to application: the impact of community intervention toimprove the delivery of preventive services to children. 2005.Available from:Pubmedwww.pubmed

26. Moy R. Integrated management of childhood illness (IMCI). Journal of Tropical Paediatrics.1998; 44:190-1.

27. Campbell JO, Sow SO, Levine MM, Kotloff KL. The causes of hospital admission and death among children in Bamako, Mali. Journal of Tropical Paediatrics. 2004.

28. American Academy of Paediatrics.Periodic survey of fellows 46. EIKGroove Village: American Academy of Paediatrics. 2001.

29. American Academy of Pediatrics. Scope of health care benefits for newborns, infants, children, and young adults through age 21 years. Pediatrics, 2006; 100(6):1040-1.

30. Ashworth A, Khanum S. Fighting malnutrition from hospital to home. Child Health Dialogue. 1996; 1(2):6-7.

31. Baldo MH, Al-Mazrou YY, Aziz KMS, Farag MK, AL-Shehri SN.Coverage and quality of natal and postnatal care: Women's perceptions, Saudi Arabia. Journal of Tropical Pedicatrics.1995; 41:30-7.

32. Barnes PM, Singh HD, Stephen AJH. A textbook of paediatrics in the tropics and subtropics.London: Macmillan Publishers; 1990.

33. Bethel C, Reuland CHP, Halfon N, Schor EL. Measuring the quality of preventive and developmental services for young children; National estimates and pattern of clinician's performance. Pediatrics.2004; 113(6):1973-83.

34. Ertem M, CakmakA, Saka G, Ceylan A. Neonatal tetanus in the southeasternregion of Turkey. Changes in prognostic aspects by better health care.Oxford: Oxford University Press.Journal of Tropical Paediatrics. 2004; 50(5):297-300.

35. Emodi I. Towards reducing mother-to-child transmission of HIV. Nigerian Journal ofPaediatrics.2002; 29(3):55-60.

36. Imershein MK,PughMathis CA,McNeece,editors. Who cares for the children: a case study of policies and practice. New York: General Hall Inc.p. 166-98.

37. Lucas AO, Gilles HM. Short textbook of public health medicine for the tropics. 4thEd. London: Book Power; 2003.

38. Schor EL. Rethinking well-child care. Paediatrics.2004; 114(1):210-6.

39. Simkiss D. Emergency paediatric care.Journal of Tropical Paediatrics.2005; 51(5):263-4.

40. Okolo SN, Adeleke OA, Chukwu GA, Egbuaba NH, Hassan A, Onwuanaku O.Immunization, and nutritional status survey of children in selected rural communities of Sokoto State. Nigerian Journal of Paediatrics.30(4);123-7.

41. Nwaneke LV, Eneh AU. Malaria Parasitemia in neonates in Port Harcourt, Nigeria. Journal of Tropical Paediatrics.2004; 50(20):114-6. 